\title{
Pragmatic Leadership Practices in Dangerous Contexts: High-Reliability Organizing (HRO) for Pandemic COVID-19
}

Daved van Stralen, MD, FAAP, Sean D. McKay, EMT-P

Thomas A. Mercer, RAdm, USN (retired)

\begin{abstract}
The threat of COVID-19 to professionals has become personal. Professionals in neonatal healthcare can acquire infection and unknowingly become a vector, infecting babies, and their colleagues. A pragmatic stance of leadership, derived from leadership in extremis, communicates to subordinates that leaders have their immediate well-being in mind while engaging in demanding situations. Effective leadership for ill-structured problems embedded in the environment has distinct characteristics such as modeling cognitive and affective skills (attitudes and the contingent value of information) and the ability to modulate emotional states. Pragmatic leaders effectively increase subordinates' collective stress capacity for, and leverage individual capabilities during, in extremis circumstances. This paper describes pragmatic leadership characteristics and practices derived from experience, primary sciences, and High Reliability Organizations (HRO).
\end{abstract}

\section{Introduction}

The threat of COVID-19 to professionals has become personal. A deadly infection acquired in the community or NICU, unknowingly becoming a vector infecting babies and their colleagues, and interference with decision-making and routine behaviors. Inadequate protective material demanded healthcare professionals improvise with locally-available resources, much like the fire department adage for improvisation, "if you don't have it, it doesn't exist." Premature infants, however, do not have the compensation capacity, makeshift material, nor the physiological reserve to survive while neonatologists determine an effective treatment. During COVID-19, neonatologists faced the dual challenge of identifying and treating a previously unencountered disease while protecting themselves and others from contracting a highly infectious virus. As such, COVID-19 is an undefined and ill-structured problem that necessitates error probing.

Healthcare leaders directing medical care now must incorporate leadership principles and practices that support and protect subordinates in a manner previously unheard of in the NICU. A pragmatic stance of leadership, derived from leadership in extremis, communicates to subordinates that their leaders have their immediate well-being in mind while engaging in new situations.

High-Reliability Situations (HRS) present disrupted structure and logic to the individual. We cannot know if an error is occurring, if we discovered a discrepancy, or if we are experiencing a new disruption to our operations. We cannot know if our hesitation to en- gage is not an error. "Look before you leap" may cause a serious error during cascading events. A threat, an uncontrollability, and the weight of demands initiate reflexive behaviors and involuntary release of neurochemicals that, though inevitable, need not be sustained. The pragmatic leader accepts the duty to increase the stress capacity, sense of controllability, and operational capability of subordinates in order to engage the HRS.

The cultural response to pandemic COVID-19 and the effect of the virus on healthcare systems revealed the effects of unrecognized fear on routine and emergency operations. Stress, as demands exceeding our abilities, is natural, expected, and leads to strength through change (allostasis). Stress responses from uncontrollability and fear reactions or sustained threat reflexes, unfortunately, have become normalized into programs expected to encounter the HRS.

\section{"The cultural response to pandemic COVID-19 and the effect of the virus on healthcare systems revealed the effects of unrecognized fear on routine and emergency operations. Stress, as demands exceeding our abilities, is natural, expected, and leads to strength through change (allostasis)."}

These circumstances disrupt care, induce unrecognized fear responses, discussed later in this article, and challenge leadership. Information for decisions is limited, uncertain, and ambiguous. Time for decisions is constrained. Unrecognized fear and sustained threat reflexes influence decisions-in-the-moment, making plausible short-term personal concerns. It is just such situations where a leader models decision making for the good of the community, a virtue, rather than self, a vice (Aristotle 2011 1140b5-7).

Phronesis - prudence or practical wisdom - is acquired by both practice and observation: practice creates the experience, while observation of elders who model this virtue leads to phronesis (Ryan 2014). Leaders stimulate people to act on their own in an interface with their environment. Practical wisdom is the capacity to choose appropriate goals and successfully devise means to reach them (Halverson 2004). Practical wisdom relies on the dynamic interaction between perception, experience, and character. It offers an insightful vision of what is proximately and ultimately

NEONATOLOGY TODAY is interested in publishing manuscripts from Neonatologists, Fellows, NNPs and those involved in caring for neonates on case studies, research results, hospital news, meeting announcements, and other pertinent topics.

Please submit your manuscript to: LomaLindaPublishingCompany@gmail.com 
good for people, organizations, and businesses. Phronesis, as prudence, is the first of Aristotle's four Cardinal Virtues (Prudence, Justice, Temperance, and Fortitude).

Leadership models developed in safe, stable environments do not generalize well in dangerous circumstances where leaders and followers must personally face dynamic and unpredictable situations, actively avoid death, and consider outcomes that include life-threatening disease or psychological injury (Kolditz 2006; Campbell, Hannah, and Matthews 2010). The sense of uncontrollability and existential threat results in stress responses and fear reactions that go unrecognized, impairing human performance and interaction (van Stralen, Byrum, Inozu 2017 269-73). Increasing stress capacity, a distinct yet inadequately developed leadership dimension in civilian leadership models, is fundamental to pragmatic HRO leadership. In this article, we will adapt the leadership characteristics of leadership in extremis and the leadership characteristics missed by the early HRO researchers into leadership for routine operations.

\section{"The pragmatic leader gives meaning to the adage 'Safety through operations and operations through safety."}

The HRO pragmatic leader increases in subordinates 1) operational and decision-making, capabilities, 2) methods to discover, acquire, and maintain a functional sense of controllability, and 3) stress capacity. The leader models values, attitudes, practical wisdom, conflicted decision-making, and modulation of stress and fear responses. Below, we describe 1) management of unrecognized stress and unrecognized fear, and 2) the elements and characteristics of leadership in extremis.

\section{Unrecognized stress, unrecognized fear}

Mild uncontrollable stress, even the sense of uncontrollability, initiates a stress response sufficient to impair cognition (Arnsten 2009). The amygdala directly impairs the executive functions, and cortisol release impairs memory recall for declarative memory (knowledge), episodic memory (experience), and working memory. Cortisol enhances procedural memory (habits and skills). Left unrecognized, the individual's abrupt inability to recall or process necessary information increases the sense of uncontrollability, mimicking an unqualified individual. A controlled physical act resolves the problem. Working memory manages 7-9 chunks of information at a time, readily occupied by system demands, rigorously mandated protocols, and fear of causing harm. We call this "unrecognized stress" when amygdala activation and cortisol-mediated stress responses become accepted as normal, expected responses rather than avoidable, serious, but recoverable performance deficits.

Maladaptive fear behaviors include protective behaviors, that is, protective of ego and reputation, and the threat reflexes. Defensive protection occurs when the individual is outside of the situation, not engaging the problem, and unfamiliar with local or immediate correlations and causations. Defensive, protective actions, directed toward saving what has not already been harmed, shift attention away from the individual's actions through deflection, excuses, justification, and "prophylactic" self-blame. Offensive protection develops within or upon entering the problem space. Offensive protective actions, to stop the spread of problems, shift attention toward the actions of others by attacking colleagues, blaming others, and making accusations. Instrumental anger, a distinct form of offensive protection, brings secondary gain for the individual. Instrumental anger, and the similar instrumental use of stress and fear, are manipulations independent of any context. Recognizing fear reactions as neurochemical responses allows the normative leader to reframe circumstances to gain the perception of controllability, reduce stress responses, and focus on the person's capabilities, system resources, re-evaluate demands, or decompose objectives for attainability.

\section{"This led to a single level of analysis rather than a macroscopic view providing multiple levels of analysis. The initial data collection and research did not identify the effect of command and leadership on the organizational structure and culture of the carrier."}

Asking residents for reasons an attending physician would become angry with them, the single common answer is that the resident made a serious mistake. They would respond by working harder. We then discussed anger as the fear fight response without the motor component. Working harder does not resolve the fear. Rather, requesting a directed action or asking, "How can I help?" moves the brain activity out of the amygdala and can resolve the anger. As reflexes, we cannot prevent the appearance of a fight, flight, or freeze, but we can modulate both motor and emotion components of the reflex to prevent sustained uncontrolled behaviors (McConnell and van Stralen 1997; Bracha 2004; van Stralen, Byrum, and Inozu 2017 285-87).

The pragmatic leader readily identifies threat reflexes and interrupts the cycle. Tonic immobility ("playing dead"), common though unrecognized, is the vagal induced "sick" feeling in the stomach (alarm bradycardia in mammals and birds) hindering decisions and actions (Alboni and Alboni 2014). Flight presents as plausible avoidance, distraction, intense review of information, or leaving to obtain equipment or information. Freeze (hypervigilance) maintains attention in preparation to act, but thinking and acting are "on hold." The leader can interrupt the threat reflex, returning the person to the team, by prompting the executive functions (ask "How can I help you?") or assigning a simple task to perform (shift to a dopamine pathway or network). In the first moments of resuscitation, a nearby nurse could not assist because of routine tasks for another patient. One of the authors (DvS) then asked the nurse to prepare a dopamine infusion, readily accomplished, and brought to the room. The author then asked the nurse for another task which the nurse undertook. Fifteen minutes into the resuscitation, the nurse asked about administering the infusion. It had not been needed. The flight response (plausible avoidance) rapidly resolved because performing a familiar task gave a sense of controllability, and the familiar task was possible because cortisol- 
induced stress enhances procedural (skill) memory.

\section{"The flight response (plausible avoidance) rapidly resolved because performing a familiar task gave a sense of controllability, and the familiar task was possible because cortisol-induced stress enhances procedural (skill) memory."}

\section{Stress Capacity}

Pragmatic leaders increase the stress capacity of subordinates by increasing demands while increasing their capacity to perform. The objective is to develop increased capability and a sense of controllability, frame experiences as challenges rather than threats, and distinguish between demands and expectations (Fisher, Hutchings, and Sarros 2010; Geraci et al. 2011; Sweeney, Matthews, and Lester 2011; van Stralen, Byrum, and Inozu 2017 pages 283-4). Context influences subordinates. Framing experiences as challenges for growth also frame the environment (Sweeney and Matthews 2011), and subordinates develop the capability for effective performance under stress conditions (Novaco et al. 1979).

The leader models the necessary attitudes and behaviors, openly discusses capabilities, core values, and shared purpose, and gives meaning to the efforts of subordinates. Attitudes influence behavior, are generalizable, and less specific, making them adaptive to varying contexts. Attitudes represent predispositions in favor of or against an element (Banaji and Heiphetz 2010, 350). For example, three years after graduating from medical school, Thomas Peebles joined the lab of Nobel Laureate John Enders to work on isolating the measles virus. Enders observed no success and removed Peebles from the project, but Peebles continued working on his own time. Peebles then isolated the measles virus used in the measles vaccine (Enders and Peebles 1954). Peebles was a US Navy aviator who flew B-24 Liberators in the South Pacific, receiving his crew's respect for his courage and leadership. He attributed his success to perseverance and a "failure to be bound by preconceived ideas" (Maugh 2010). Perseverance, courage, and acceptance of the novel are attitudes also found in naval aviators.

Pragmatic leaders treat all subordinates fairly, independent of the leader's feeling or judgment toward the subordinate. It is not uncommon, if not accepted, for a leader to marginalize subordinates through nonverbal cues and obtuse comments. Subordinates will notice a colleague who has become marginalized by the leader and, even if others do not favor the subordinate, the leader's actions negatively affect group performance. Actions by the leader are what create trust. Trust was a central factor in defining the characteristics of leading in combat during the Vietnam War (Fisher, Hutchings, and Sarros 2010).

\section{Controllability}

Controllability not only averts the cortisol-mediated memory impairment (cortisol released due to uncontrollable stress), it is also the objective for first actions. That is, through sensing (not sense- making), the individual identifies an action to take, observes the response to the action, then acts on that information (McConnell and van Stralen 1997; van Stralen, Byrum, and Inozu 2017 183$4)$. The goal is to identify any point of controllability.

Leadership can instruct subordinates in methods to identify controllability during crises. One of the authors (DvS) sent a PGY2 pediatric resident to stabilize and transport an infant actively being resuscitated in the emergency department (ED) of a local major medical center. The pediatric resident later described the hypervigilant freeze response that came over her, she could not think. After the sensation started, she checked the endotracheal tube to see if it was working. It was working before checking, but it was the physical activity she wanted, and it was that physical activity that broke the freeze. The transport resident successfully resuscitated the infant within 20 minutes and returned with the child to the PICU (van Stralen, Byrum, and Inozu 237-8).

\section{Expectations and demands}

On the tactical level, during an emergency or crisis, we can too easily confuse expectations with demands. (The military refers to demands as constraints and limitations: what you must and cannot do.) Demands are objective, have a practical pathway that can be developed, a clearly identified end state, and can be described in concrete terms without abstractions, metaphors, or the use of clichés. Demands are the priority for the pragmatic HRO stance. Expectations, on the other hand, are subjective, vague, even nebulous, and are more often described in the abstract or through metaphors. Expectations may appear concrete and objective, but they lack the practicality of developing a path from the situation to the end state. Demands are more likely to be independent of the context and person, have objective markers to show progress, and have measurable endpoints. Expectations more likely come from desire or imperfect knowledge and depend on the strength of personal or group beliefs. Expectations too readily replace or become confused with demands. Striving for an expectation frames the situation or problem improperly, creates uncontrollability, generates gratuitous stress, impairs individual and team performance, and builds toward traumatic stress. A demand we cannot reach because of efforts and resources directed toward an expectation is a preventable tragedy.

\section{Cognitive Appraisal and Traumatic Stress}

Operations in a demanding, life-or-death environment, whether the NICU, public safety, or military operations, create two trajectories for psychological health: resilience or traumatic stress (Geraci et al. 2011). While there are numerous contributing factors, the NICU attending's use of leadership in dangerous contexts can decrease the likelihood of the traumatic stress trajectory and enhance the likelihood of the resilience trajectory. Cognitively appraising experiences and training as threatening, by the subordinate, contributes to later poor psychological health and impaired resilience (Geraci et al. 2011). Collegiate athletes also show similar differences when they appraise experience as a threat versus a challenge, the latter is a problem solver's perspective. Leadership is not restricted to organizational line authority, allowing the neonatologist to influence the cognitive appraisal of events by NICU staff and the families of patients. Using the same methods military leadership in extremis uses with soldiers (Geraci et al. 2011; Sweeney and Matthews 2011; Sweeney, Matthews, and Lester 2011), the neonatologist can reduce the incidence of post- 
traumatic stress and contribute to post-traumatic growth in staff and families (Aftyka et al. 2017; Rodríguez-Rey et al. 2017; Wu et al. 2019; Aftyka, Rozalska, and Milanowska 2020). Post-traumatic growth is the psychological, emotional, and spiritual growth found after extreme traumatic experiences (Tedeschi and Calhoun 2004; Calhoun and Tedeschi 2014)

The trajectory begins with the first independent decision a subordinate makes and is repeated with the first decision the subordinate makes that others will rely on. Gastric distress due to the tonic immobility reflex induces avoidance of decisions. Recognizing this, and with some risk to his professional reputation, one of the authors (DvS) routinely compelled staff to make their first final decision in front of him, this is the decision the team would act on without review, even for medications administered "as needed." Discussions ensued to identify and correct a decision that didn't work and the presentation of a "decision box": what would happen if we gave too much or not enough, or acted too soon or too late? Identifying a "box" within which it was safe to decide and act, while identifying the dangers of over or under treating, supported initiative on the part of the subordinate.

\section{"The trajectory begins with the first independent decision a subordinate makes and is repeated with the first decision the subordinate makes that others will rely on."}

"Leaders of HRO systems, under no existential threat themselves in treating patients, can become normative, procedural, and algorithmic. This does not work well in a room with a contagious COVID-19 patient or pre-symptomatic staff. This new threat happens all the time in a military fight zone or during operations by Special Operations Forces. With the pragmatic leadership stance, I imagine, all personnel will be much calmer because information and authority will flow among them much easier." Errol van Stralen, Ancora Education.

\section{Elements of pragmatic leadership}

The pragmatic stance is not about the leader entering a difficult environment, but how the leader's behavior influences the wellbeing of subordinates, so they not only enter the environment but effectively perform (Kolditz 2006). Working the problem from within the situation, sharing threats and uncertainty as a participant, defines the pragmatic leadership stance. The ill-structured problem is a natural system that becomes ordered from internal processes, a self-organizing system. The team, and leader, must enter the system, becoming part of the internal processes that generate order. We cannot organize the situation and use commands and rules to resolve ill-structured problems from the outside as is possible with context-independent, well-structured problems.

\section{The problem situation}

The pragmatic leadership stance prepares subordinates to engage undefined and ill-structured problems, interact with processes internal to the system, then share experiences with others to make the HRO stronger. The leader guides engagement through participation and closes the gaps between discrete concepts, continuous perceptions (Weick 2011), and between theory and practice (Zundel and Kokkalis. 2010; van Stralen 2020).

Leadership from the pragmatic stance, the foundation of HRO, is directional and developmental. The directional component carries a team into an environment characterized by disorder or randomness, lack of identifiable structure, instability, and unpredictability. The developmental component moves the novice toward decisionmaking that is less influenced by unrecognized fear. To identify the necessary leadership characteristics for the pragmatic stance, we look to leadership in extremis or leadership in dangerous contexts, a type of leadership in organizations with a long history of dangerous operations. Leadership skills in these organizations include use of contingent principles, context-dependent information, affective and cognitive thought processes (Palmer, Hannah, and Sosnowik 2011; van Stralen et al. 2017 82-87), and development of "swift trust" as groups rapidly form then dissolve to reform later or elsewhere (Meyerson, Weick, and Kramer 1996).

\section{Leader-Leader; Leader-Follower}

We expect, in the pragmatic stance, to develop "leader-leaders" (van Stralen, Byrum, and Inozu 2017). Staff in the NICU must immediately engage any disruption and investigate any discrepancy, not delaying for contact with the neonatologist. When a novel, unexpected event occurs, we expect someone to engage in some manner. In the pragmatic stance, people lead the problem until they are relieved.

Followership is the capacity to follow. We acknowledge that some executives, administrators, and managers consider followership the willingness to follow, but that view brings focus on conformity, obedience, and submission. Few, if any, traits are unique to followers in the pragmatic stance that are not also found in leaders. What may appear as bad followership may actually be good leadership for a problem when observed from a different point of view.

\section{"Staff in the NICU must immediately engage any disruption and investigate any discrepancy, not delaying for contact with the neonatologist. When a novel, unexpected event occurs, we expect someone to engage in some manner."}

\section{Elements of pragmatic leadership stance}

\section{Distributed Knowledge}

An emergency creates its own, unstable environment which contains new, evolving information. Teamwork develops as an emergent property, a stabilizing structure, to facilitate shared sensemaking (Maitlis and Christianson 2014; Dixon et al. 2017; van Stralen, Byrum, and Inozu 2017 396). Information changes with time, and what happens at any moment will continually influence what happens next, sequentially, and reciprocally (Dixon et al. 2017; van Stralen, Byrum, and Inozu 2017 396). The rapidity of 
these developments, and the stabilizing effect of the team, occur before the leader arrives, a characteristic of dangerous contexts. When team members believe they are less competent than the leader, they will also have less influence on each other, impairing efforts to achieve high performance. Team members who can influence the leader and each other perform better in the absence of leadership (Ramthun and Matkin 2014).

\section{Reciprocal Influence and Trust}

The greatest distinction between healthcare and those working in an in extremis environment is the acceptance of trust. One of the authors (DvS) assumed care of an infant experiencing abrupt, severe upper airway obstruction. The surgeons requested an examination before intubation, if possible. Notified of the severe obstruction, the resident surgeon resisted responding. Only after speaking with the chief of service did the surgeons respond. The same author, as a paramedic, responded to a house for an assault victim, a juvenile with an intellectual disability. The assailant in the room threatened to shoot the paramedics if they continued treating the child. The assailant left the house to get a gun with everyone in the house running out. The author called fire dispatch, saying, "A kid said he's going to shoot us." The dispatcher replied, simply, "We'll get you the help you need." The author left the house to prevent the assailant from returning. A helicopter arrived at low altitude, six police cars arrived together, smoke from the brakes filling the street, followed by more. A fire engine arrived, its brakes adding to the smoke. A battalion chief arrived. (The police did apprehend the assailant.) This is the difference between high trust and low trust, between operating routinely in a stable environment and operating in an unsafe environment.

\section{"When team members believe they are less competent than the leader, they will also have less influence on each other, impairing efforts to achieve high performance. Team members who can influence the leader and each other perform better in the absence of leadership (Ramthun and Matkin 2014)."}

Trust is often considered a transaction, often dependent, unfortunately on the "other" person, the outsider, or the new member. Drawing from one of the author's (DvS) experiences from winter mountaineering, and unaccompanied rescue ambulance responses in drug and gang areas, he learned that one never enters a situation where you cannot extricate both yourself and your partner. That is trust in yourself for the capability to help others and yourself. The reason is that you might be the one who needs extrication. A fire department phrase, "If you don't trust me, you can't be trusted."

The goal is for trust to initiate reciprocity, maturing to mutual influence, culminating in shared leadership. Along the way, detection of weak signals, sorting out noise, and the flow of information dramatically improve with earlier detection of the covert, compensated phase of a process. Inductive processes extend HRO into adverse or hostile environments. Inductive processes depend on accurate description of observable phenomena, the very thing trusted subordinates, communicating through reciprocity, will generate and be supportive of "deference to expertise." Blind spots become visible, information removes uncertainty, and meaning resolves the ambiguity. The meaning of the vignette about US Navy SEALs becomes clear. "All personnel will be much calmer because information and authority will flow among them much easier."

Studies of leadership in extremis, from the Vietnam War to the present, found that trust and mutual influence are the keys to shared leadership (Fisher Hutchings, and Sarros 2010; Ramthun and Matkin 2014). Trust and reciprocity form the basis of collective sense-making in dangerous contexts (Baran and Scott 2010; Campbell, Hannah, and Matthews 2010; Dixon et al. 2017). Similarly, in firefighting, shifting events may suggest to individuals that hazards are unfolding or developing, but contextual ambiguity ensures that the nature and essential significance of these hazards are frequently open to multiple and conflicting interpretations. Such leadership (i.e., collective sense-making) results from the ongoing, reciprocal interactions among all the team participants in the situation, regardless of their formal organizational rank or authority.

The evidence from leadership in extremis studies shows that, when the leader adjusts plans based on information submitted by a subordinate, it creates greater trust in the leader, increased sharing of information, and increased communication to the leader. Mutual interdependence, rather than trust in the leader, can explain how leaders may earn subordinate trust, and be perceived as credible. Proactive solicitation of suggestions demonstrates there is no one right answer or perspective, encouraging divergent thinking (Barton et al. 2015).

The team becomes structured through internal, self-organizing processes driven by mutual framing, distributed knowledge, a common threat, and shared sense-making/sense giving. Military veterans describe the importance of mutual influence on performance in extremis, the mutual influence acting as a multidirectional pattern of reciprocal leadership, enabling team members to lead each other to achieve common objectives (Ramthun and Matkin 2014). For polar explorers, this reciprocal influence makes the team highly effective while the leader maintains a strong influence (Karrasch, Levine, and Kolditz 2011). The leader who seeks perspectives, encouraging the sharing of information, models on how to engage ambiguous situations (Barton et al. 2015). Leadership in dangerous contexts, then, becomes a collective undertaking, with influence fluidly moving to the site it is needed, while team members gain a common, and increasingly accurate understanding, of the situation (Campbell, Hannah, and Matthews 2010; Fisher, Hutchings, and Sarros 2010). Through reciprocal influence, the leader gains a sense of how members think and

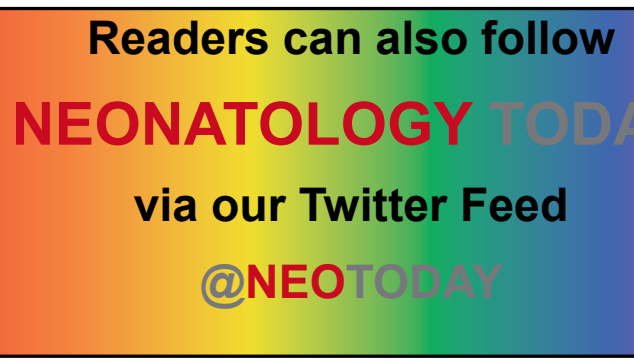

via our Twitter Feed

@NEO 
their motivation (Karrasch, Levine, and Kolditz 2011).

Reciprocal influence toward resuscitating an infant, as a form of altruism, is associated with reward processing in the brain and is related to resilience (Charney 2003). Leadership becomes an emergent property with sustained social cooperation in dangerous contexts, with different leaders emerging serially based on expertise and knowledge. The serial emergence of leaders provides "leader sustainability" (Ramthun and Matkin 2014).

\section{Framing}

Self-awareness allows leaders to frame experiences as challenges to increase growth (Sweeney and Matthews 2011). How the leader frames the situation guides followers, whether it is worthy of greater vigilance and exploration, and the leader's behavior will model engagement as a problem-solving strategy (Barton et al. 2015). Framing selects and calls attention to particular aspects of reality, allowing us to filter information, give meaning to perceptions, organize experience, and guides actions. We then create basic cognitive structures that guide our perception of reality. A leadership process used by firefighters continually adjusts their framing in dangerous contexts to not only maintain awareness of their surroundings through continual interaction but also to continuously keep themselves poised for a shift of action as the situ-

\section{"Leadership becomes an emergent property with sustained social cooperation in dangerous contexts, with different leaders emerging serially based on expertise and knowledge. The serial emergence of leaders provides "leader sustainability" (Ramthun and Matkin 2014)."}

ation evolves (Baran and Scott 2010). The subordinate's framing supports common sense-making and sense-giving reciprocity with the leader, particularly in an in extremis situation (Dixon et al. 2017). Framing, as a learned personal and social skill for in extremis situations, should then come from the neonatologist.

In the flux of a neonatal emergency, the frame rapidly changes, yet no one participant can experience another's frame. When the frame changes, what rules also change, and which rules remain? (This is the frame problem from artificial intelligence.) "The first inchoate 'sense' that a leader and his command may be in extremis triggers a sense-making/sense-giving cycle," continually refining or revising both (Dixon et al. 2017). Team members and the leader engage in sense-making/sense-giving as interactive, iterative, recursive, intertwined, and overlapping parts of a single process. Each action, rapid shifts in contingencies, and unexpected disruptions change some of the rules. More than group interaction, it is through shared cognition and visual communication (Baran and Scott 2010; Dixon et al. 2017; van Stralen et al. 2017 104) that the team generates a frame that, while dynamically changing, becomes an increasingly accurate representation of events.

\section{Conflicting objectives}

Bill Corr, Captain, LAFD, and a South Pacific WWII US Navy veteran, and his firefighter took advantage of a fence and low roof to rapidly gain access in order to cut a ventilation hole at a house fire. The arriving Battalion Chief called out, "Corr! Don't you know it's department policy to always have a ladder when you're on the roof?!" Capt Corr shouted back, "Isn't it also department policy to put out the fire?!"

During an emergency, we maintain a dynamic balance between opposing principles, simultaneously increase the chance of success while decreasing the possibility of failure. There will be times we lose synchrony, and we disagree on principles to use or actions to take. Active, reciprocal involvement of the leader during routine operations supports decision making when ambiguity and equipoise worsen the conflicting objectives and solutions typical of the ill-structured problem. For example, in order to win the "hearts and minds' of villagers, soldiers will give up their safety to patrol on foot, exposing themselves to improvised explosive devices leading to personnel losses by bombs and shootings. The "show friendliness" makes contact easier with the local population versus increased protection that damages relationships with the local population (Vogelaar, Van den Berg, and Kolditz, 2010). "Short feedback" favors force protection over civilian contact while "delayed feedback" or "indirect feedback" favors closer contact with civilians. Short feedback protects in the immediate environment, similar to short feedback ("error") in resuscitation - it uncovers threat and reveals the boundary of the safe operational envelope. "Long feedback" contributes to growth, accumulates over time, and is unnoticed in the heat of the emergency. "Indirect feedback," as a form of wisdom and teaching, employs immediate actions to put in place ideas or structures that benefit a later group. "Delayed feedback," a hallmark of neonatology, protects nascent tissues, the effect which cannot be known for years.

The pragmatic leader, aware of these distinctions, guides the team through actions that will produce effects on a variety of timelines.

"The captain then said, "There are a
thousand things happening on the scene.
You can only see a hundred. You can only
act on ten. I may see a different hundred.
I may act on a different ten. That doesn"t
mean I'm better than you;, only that I'm
different." Even if engaged side by side,
people experience different forms of
sense-making in unexpected events."

\section{Conclusion}

The pragmatic leadership stance increases the mental and psychological capabilities of staff. The qualities of the HRO pragmatic leader enable the smooth implementation of HRO and support identification and engagement of early heralds of failure. The neonatologist, using the pragmatic leadership stance, can improve performance and effective operations while reducing uncontrol- 
lable stress in the NICU for the benefit of the babies, families, and staff.

How the leader responds to errors and failures demonstrates internalization of these leadership characteristics. The following vignettes also reveal the long-term growth the pragmatic leader initiates.

A senior physician at a university medical center believed the critical care fellows should have a deep appreciation for the responsibilities they have providing care. If the fellow made an error that contributed to a child's death, the attending expected the fellow to cry. If the fellow did not cry, the attending personally counseled the fellow, believing that all fellows should cry at least once during training. If the fellow still did not cry, the attending believed the fellow had no feelings for the children.

One of the authors (DvS), working on a fire rescue ambulance, managed a motor vehicle collision with the unconscious victim trapped in the car. Because of miscommunications and misjudgments, the responding fire apparatus did not have the necessary extrication tools, delaying transportation of the patient to the hospital. The patient died that evening. That evening, the fire captain thanked the author for his efforts, telling him he was the most qualified rescue ambulance driver the fire department had at the time of the call and that the department would support him and everything he did. Then he opened a discussion of what could be done differently, developing reasons for each decision point. The captain concluded by restating the author was the most qualified rescue ambulance driver the department had for the call so that the department would stand behind the driver and his actions.

The captain then said, "There are a thousand things happening on the scene. You can only see a hundred. You can only act on ten. I may see a different hundred. I may act on a different ten. That doesn't mean I'm better than you; only that I'm different." Even if engaged side by side, people experience different forms of sensemaking in unexpected events.

"This remains, to me, one of your more powerful, rich experiences. One can dwell on its implications for a long time." Karl Weick, personal communication.

\section{References}

Aftyka, Anna, Ilona Rozalska-Walaszek, Wojciech Rosa, Beata Rybojad, and Hanna Karakuła-Juchnowicz. 2017. "Posttraumatic growth in parents after infants' neonatal intensive care unit hospitalisation." Journal of clinical nursing 26(5-6): 727-34.

Aftyka, Anna, Ilona Rozalska, and Joanna Milanowska. 2020. "Is post-traumatic growth possible in the parents of former patients of neonatal intensive care units?" Annals of Agricultural and Environmental Medicine 27(1): 106-12.

Alboni, Paolo, and Marco Alboni. 2014. "Vasovagal syncope as a manifestation of an evolutionary selected trait." Journal of atrial fibrillation 7(2): 97-102.

Aristotle. 2011. Nicomachean Ethics Trans. Bartlett, Robert C., Susan D. Collins. Chicago, Illinois: The University of Chicago Press.

Arnsten, Amy F., 2009. "Stress Signaling Pathways That Impair Prefrontal Cortex Structure and Function." Nature Reviews Neuroscience 10(6): 410-22.

Banaji, Mahzarin R., and Larisa Heiphetz. 2010. "Attitudes." In
Handbook of Social Psychology, edited by S. T. Fiske, D. T. Gilbert, and G. Lindzey, 353-93. Hoboken, NJ: John Wiley.

Baran, Benjamin E., and Cliff W. Scott. 2010. "Organizing ambiguity: A grounded theory of leadership and sense-making within dangerous contexts." Military Psychology 22 (Supplement 1): S42-S69

Barton, Michelle A., Kathleen M. Sutcliffe, Timothy J. Vogus, and Theodore DeWitt. 2015. "Performing under Uncertainty: Contextualized Engagement in Wildland Firefighting." Journal of Contingencies and Crisis Management 23(2): 74-83.

Bracha, H.Stefan. 2004. "Freeze, flight, fight, fright, faint: Adaptionist perspectives on the Acute Stress response Spectrum." CNS Spectrums 9(9): 679-85.

Calhoun, Lawrence G., and Richard G. Tedeschi. 2014. "The Foundation of Posttraumatic Growth: An Expanded Framework." In Handbook of Posttraumatic Growth: Research and Practice, edited by Lawrence G. Calhoun and Richard G. Tedeschi, 1-23. New York, NY: Routledge.

Campbell, Donald J., Sean T. Hannah, and Michael D. Matthews. 2010, "Leadership in military and other dangerous contexts: Introduction to the special topic issue." Military Psychology 22 (Supplement 1): S1-S14.

Charney, Dennis S., 2003. "Neuroanatomical circuits modulating fear and anxiety behaviors." Acta Psychiatrica Scandinavica 108 (Supplement 417): 38-50.

Dixon, Deirdre P., Michael Weeks, Richard Boland Jr, and Sheri Perelli. 2017. "Making sense when it matters most: An exploratory study of leadership in extremis." Journal of Leadership \& Organizational Studies 24(3): 294-317.

Enders, John F., and Thomas C. Peebles. 1954. "Propagation in tissue cultures of cytopathogenic agents from patients with measles." Proceedings of the Society for Experimental Biology and Medicine 86(2): 277-286.

Fisher, Kelly, Kate Hutchings, and James C. Sarros. 2010. "The 'bright' and 'shadow' aspects of in extremis leadership." Military Psychology 22 (supplement 1): S89-S116.

Geraci, Joseph, Mike Baker; George Bonanno, Barend Tussenbroek, and Loree Sutton. 2011. "Understanding and Mitigating Post-Traumatic Stress Disorder." US Army Research. In Leadership in Dangerous Situations: A Handbook for the Armed Forces, Emergency Services, and First Responders, edited by Patrick J. Sweeney, Michael D. Matthews, and Paul B. Lester, 78-96. Annapolis: Naval Institute Press.

Halverson, Richard. 2004. "Accessing, Documenting, and Communicating Practical Wisdom: The Phronesis of School Leadership Practice." American Journal of Education 111(1): 90-121.

Karrasch, Angela, Alison Levine, and Thomas Kolditz. 2011. "Chapter 12. Leadership When It Matters Most Lessons on Influence from In Extremis Contexts." In Leadership in Dangerous Situations: A Handbook for the Armed Forces, Emergency Services, and First Responders edited by Patrick J. Sweeney, Michael D. Matthews, and Paul B. Lester, 218-29. Annapolis: Naval Institute Press.

Kolditz, Thomas A. 2006. "Research in in extremis settings: expanding the critique of 'why they fight.'" Armed Forces \& Society 32(4): 655-58.

Maitlis Sally, and Marlys Christianson. 2014. "Sense-making in 
Organizations: Taking Stock and Moving Forward." Academy of Management Annals 8(1): 57-125.

Maugh, Thomas H., II. 2020. "Thomas C. Peebles dies at 89; doctor isolated measles virus." [Obituary] LA, CA: Los Angeles Times.

McConnell, Mark, and Daved van Stralen. 1997. "Emergency Medical Decision Making in the Tactical Environment." Tactical Edge Journal 15(3): 32-9.

Meyerson, Debra, Karl E. Weick, and Roderick M. Kramer. 1996. "Chapter 9. Swift trust and temporary groups." In trust in organizations: Frontiers of theory and research edited by Roderick M. Kramer and Tom R. Tyler, 166-95. Thousand Oaks, CA: Sage Publications.

Novaco, Raymond W., Irwin G. Sarason, Thomas M. Cook, Gregory L. Robinson, and Francis J. Cunningham. 1979. "Psychological and Organizational Factors Related to Attrition and Performance in Marine Corps Recruit Training." Arlington, VA: Office of Naval Research.

Palmer, Noel F.; Sean T. Hannah, and Daniel E. Sosnowik. 2011. "Chapter 19. Leader Development for Dangerous Contexts" In Leadership in Dangerous Situations: A Handbook for the Armed Forces, Emergency Services, and First Responders, edited by Patrick J Sweeney, Michael D. Matthews, and Paul B. Lester, 350-69. Annapolis: Naval Institute Press.

Ramthun, Alex J., and Gina S. Matkin. 2014. "Leading dangerously: A case study of military teams and shared leadership in dangerous environments." Journal of Leadership \& Organizational Studies 21(3): 244-56.

Rodríguez-Rey, Rocío, Alba Palacios, Jesús Alonso-Tapia, Elena Pérez, Elena Álvarez, Ana Coca, Santiago Mencía, Santiago Marcos, Ana Maria Mayordomo-Colunga, Juan Fernández, F. and Francisco Gomez, et al. 2017. "Posttraumatic growth in pediatric intensive care personnel: Dependence on resilience and coping strategies." Psychological Trauma: Theory, Research, Practice, and Policy 9(4): 407-15.

Ryan, Sharon. "Wisdom." In The Stanford Encyclopedia of Philosophy (Winter 2014 edition), edited by Edward N. Zalta. https://plato.stanford.edu/archives/ win2014/entries/wisdom/.

Sweeney, Patrick J., and Michael D. Matthews. 2011. "Chapter 20. A Holistic Approach to Leading in Dangerous Situations." US Army Research 357 in Leadership in Dangerous Situations: A Handbook for the Armed Forces, Emergency Services, and First Responders, edited by Patrick J. Sweeney, Michael D. Matthews, and Paul B. Lester, 375-91. Annapolis: Naval Institute Press. http://digitalcommons.unl.edu/usarmyresearch/357

Sweeney, Patrick J. Michael D. Matthews, and Paul B. Lester. 2011. "Leading in Dangerous Situations An Overview of the Unique Challenges." US Army Research. 355. http:// digitalcommons.unl.edu/usarmyresearch/355

Tedeschi, Richard G., and Lawrence G. Calhoun. 2004. "Posttraumatic Growth: Conceptual Foundations and Empirical Evidence." Psychological Inquiry 15(1): 1-18.

van Stralen, Daved. 2020. "Pragmatic High-Reliability Organization (HRO) during Pandemic COVID-19." Neonatology Today 15(4): 1-9.

van Stralen, Daved, Spencer Byrum, and Bahadir Inozu. 2017. High Reliability for a Highly Unreliable World: Preparing for Code Blue through Daily Operations in Healthcare. North Charleston, SC: CreatSpace Publishing.

van Stralen Daved, Sean McKay, George T. Williams, and Thomas A. Mercer. 2017. Tactical Improvisation: After-Action Report of the Active Shooter Incident Response by the San Bernardino City Fire Department December 2, 2015. San Bernardino, CA: San Bernardino County Fire Department.

Vogelaar, Ad, Coen van den Berg, and Thomas Kolditz. 2010. "Leadership in the face of chaos and danger." In Managing Military Organisations: Theory and Practice edited by Joseph Soeters, Paul C. van Fenema, and Robert Beeres, 113-25. London/New York: Routledge.

Weick, Karl E., 2011. "Organizing for Transient Reliability: The Production of Dynamic Non-Events." Journal of Contingencies and Crisis Management 19(1): 21-7.

Wu, Xiaoli, Atipatsa C. Kaminga, Wenjie Dai, Jing Deng, Zhipeng Wang, Xiongfeng Pan, and Aizhong Liu. 2019. "The prevalence of moderate-to-high posttraumatic growth: A systematic review and meta-analysis." Journal of affective disorders 243: 408-15.

Zundel, Mike, and Panagiotis Kokkalis. 2010. "Theorizing as engaged practice.” Organization Studies 31(9-10): 1209-27.

Disclosure: The authors have no disclosures.

NT

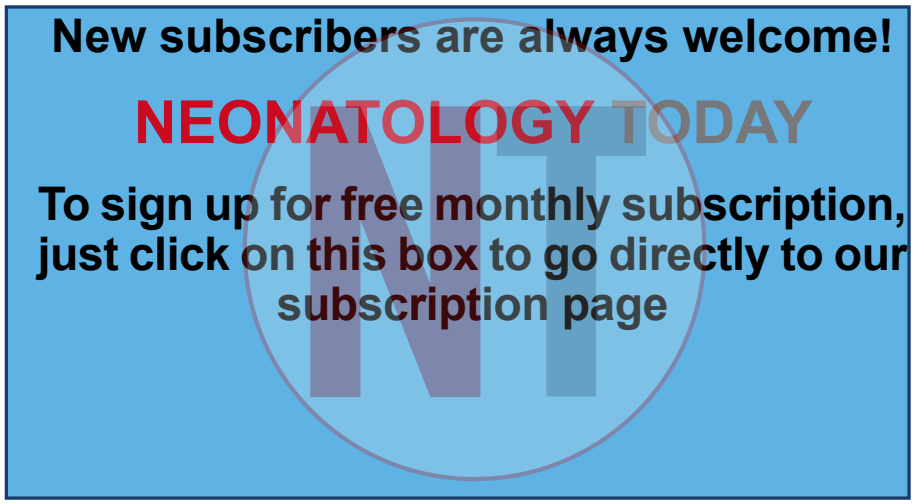

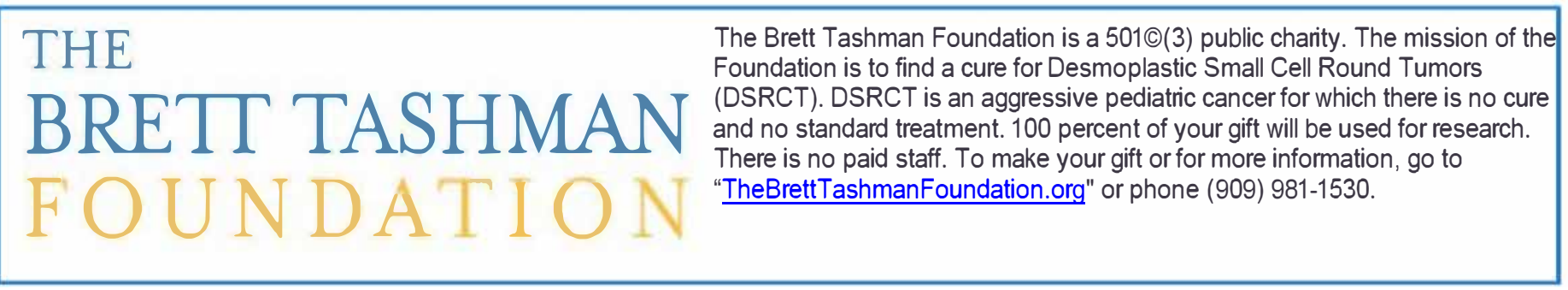




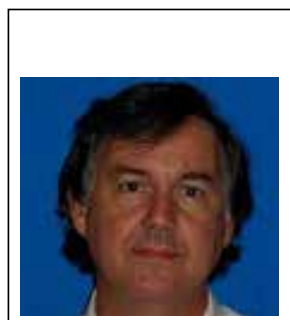

Daved van Stralen, MD, FAAP

Associate Professor, Pediatrics

Department of Pediatrics

Loma Linda University School of Medicine

11175 Campus Street

CP-A1121

Loma Linda, CA 92350

Email: DVanStra@llu.edu

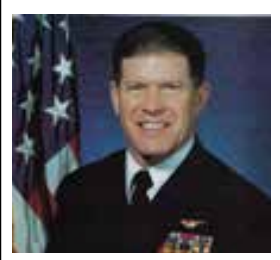

Thomas A. Mercer, RAdm, USN (retired)

Superintendent

Naval Postgraduate School

(Jan 1993-Sep 1995)

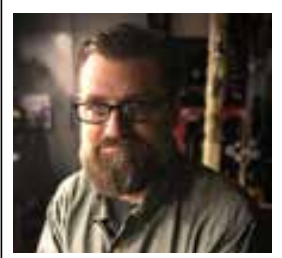

Sean D. McKay, EMT-P

COO \& Director

Austere Medicine and High Threat Rescue

Element Rescue

www.elementrescue.com

\section{Acknowledgments}

Karl Weick, Rensis Likert Distinguished University Professor of Organizational Behavior and Psychology, Emeritus, University of Michigan

Errol van Stralen, Ancora Education

Jason Amerson, MSG, USASOC

William Gambino, CIV, DoD

Dale Marsden, Ed. D., former Superintendent, San Bernardino City Unified School District

Roger Bush, a former commissioner on Joint Commission, and chair of its "Achieving High Reliability Task Force"

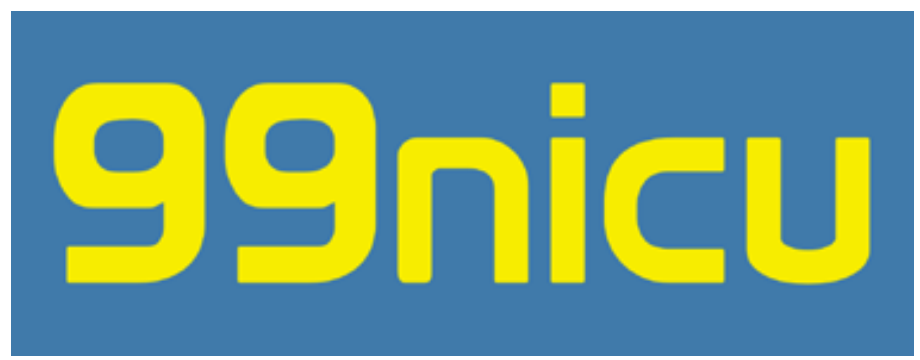

NATIONAL PERINATAL ASSOCIATION

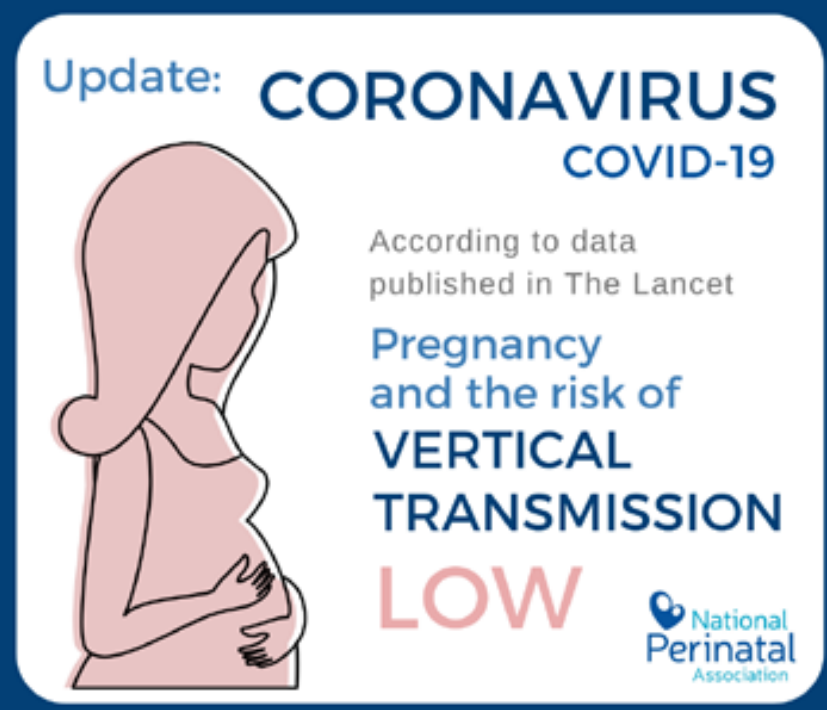

www.nationalperinatal.org

\section{Time is precious, just like your patients.}

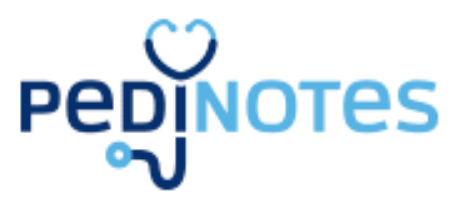

